\title{
Correction to: Improved submucosal tunneling endoscopic resection with slant tunnel for submucosal tumors in proximal esophagus
}

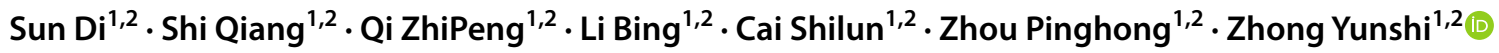

Published online: 31 August 2021

○) Springer Science+Business Media, LLC, part of Springer Nature 2021

Correction to: Surgical Endoscopy (2021) 35:4055-4060 https://doi.org/10.1007/s00464-021-08503-0

This article originally published with incorrect tables. This article has been updated to correct the tables.

Publisher's Note Springer Nature remains neutral with regard to jurisdictional claims in published maps and institutional affiliations.

The original article can be found online at https://doi.org/10.1007/ s00464-021-08503-0.

Zhou Pinghong

zhou.pinghong@zs-hospital.sh.cn

$\triangle$ Zhong Yunshi

zhongyunshi@yahoo.com

1 Endoscopy Center, Zhongshan Hospital of Fudan University, Shanghai 200032, China

2 Endoscopy Research Institute of Fudan University, Shanghai 200032, China 